\title{
Attraction to Physical Activity for Youth Who Are BVI/DHH at a Residential School
}

\author{
Stefan Ward ${ }^{1}$, Charles Farnsworth ${ }^{2}$, Megan Babkes ${ }^{2}$, and Jamis Perrett ${ }^{3}$ \\ ${ }^{1}$ Central Washington University \\ ${ }^{2}$ University of Northern Colorado \\ ${ }^{3}$ Texas A\&M University
}

\begin{abstract}
Youth who are blind or visually impaired (BVI) and youth who are deaf or hard of hearing (DHH) often have low participation in sport and regular physical activity. Minimal research has sought to explore the variables associated with relatively low involvement in sport and physical activity among youth with BVI and/or DHH at residential schools. Financial situations and budget cuts have forced many states to combine residential schools for low incidence disabilities such as BVI \& DHH. The purpose of the present study was to investigate the nature of attraction to physical activity for those attending a residential school for DHH and BVI. Semi-structured interviews were conducted with 11 school residents ( $\mathrm{n}=5$ blind; 3 male, 2 female and $\mathrm{n}=6$ deaf; 4 male, 2 female) who ranged in age from 10-18 years. Deductive content analyses revealed a number of meaningful themes in each category for both disability groups. Findings suggest that both hearing and visually impaired youth enjoyed physical activity and valued health benefits. However, this desire did not translate into being physically active. Youth suggested barriers for this including low parental encouragement for sport and physical activity and some social exclusion from non-disabled peers in game settings.
\end{abstract}

(C) 2012 Californian Journal of Health Promotion. All rights reserved.

Keywords: Visual impairment, Deaf/hard of hearing, Physical activity, Adapted Physical Education, Qualitative

\section{Introduction}

Maintaining a high level of fitness is associated with physical, social, and mental well being (U.S. Department of Health \& Human Services, 2000). Lack of attention to maintaining a high level of fitness is creating an obesity crisis in the U.S. so significant that it is now considered one of the most important public health problems of this generation (Simons-Morton, Obarzanek, \& Cutler, 2006). This includes persons with disabilities (Brown, Balluz, Heath, Moriarty, Ford, Giles, \& Mokdad, 2003; CapellaMcDonnall, 2007). Of the 54 million of Americans with disabilities, over half do not engage in any leisure-time physical activity (U.S. Department of Health \& Human Services, 2000).

\section{Research in Low Incidence Populations}

Although there is not as much research for low incidence disability populations, such as people who are blind or visually impaired (BVI) and those who are deaf or hard of hearing (DHH), the levels of reported physical activity for these populations are alarmingly low (CapellaMcDonnall, 2007; Holbrook, Caputo, Perry, Fuller, \& Morgan, 2009). Studies suggest that students with BVI have significantly less physical fitness and activity levels than youth without these disabilities (Kozub \& Oh, 2004; Harrison, 2006; Liberman, Byrne, Mattern, Watt, \& Fernandez-Vivo, 2010; Lieberman \& McHugh, 2001; Longmuir \& Bar-Or, 2000). Often, a lack of regular physical activity and/or other factors develops into co-morbidities (multiple problems) which can include: poor 
circulation, limited lung capacity, poor muscle tone, poor posture, and a tendency towards obesity (Letcher, n. d.; Lieberman \& Wilson, 2005).

Psychologically, a sedentary lifestyle can also lead to negative feelings of anxiety, low selfesteem, depression, low confidence, and poor self-efficacy (Brooks \& Ellis, 1982; Holbrook, et al., 2009; Stuart, Lieberman, \& Hand, 2006). Regular physical activity can help to prevent or alleviate many of these problems, especially for children who are (BVI) or (DHH) and require planned vigorous activity to offset sedentary lifestyles (Williams, 1988). Physical activity can help to reduce the negative effects of anxiety, stress, and depression (Morgan, 1994).

\section{Influence on Physical Activity}

Physical activity levels in youth have been linked to parental influences such as the value parents place on physical activity (Dempsey, Kimieciek, \& Horn, 1993). Ayvazoglu, Oh, and Kozub (2006) found that during a BVI summer program for children, participants with the highest activity rate also had the highest parental involvement. For the other participants parental activity was lower than child and sibling activity. Stuart, Lieberman, and Hand (2006) found in both parents and children associated decreased levels of vision with lower expectations for success at physical activity. Ellis (2001) found similar results for students who are DHH. It was found that students with more supportive parents, who were also $\mathrm{DHH}$, did up to $80 \%$ better on fitness testing than those with unsupportive parents who were hearing.

Over-protectiveness and lower expectations of parents often contributes to the formation of sedentary tendencies among children who are BVI (Bishop, 2000; Fiorni, Stanton, \& Reid, 1996). The attitudes of physical education teachers and adapted physical education teachers also impacts the fitness and activity levels of youth who are BVI and/or DHH (Kiavina \& Roswal, 2003; Liberman, Houston-Wilson, \& Kozub, 2002; Robinson, Lieberman, \& Rollheiser, 2005). These teachers may be overprotective, unsure of safety procedures, or inexperienced in dealing with youth with sensory impairments like BVI and DHH.

Adults and youth who are BVI with these disabilities often have a host of barriers that work against their being active. Factors like parental over-protectiveness, lack of opportunities, co-morbidity, prejudice and misconceptions of others, and transportation issues often hinder an active lifestyle for students who are BVI (Gosch, Bambring, Gennat, \& Rohlman, 1997; Lieberman \& Houston-Wilson, 1999). Tepfer (2002) suggested low participation of peers willing to participate was also a large factor affecting these populations. A trend toward a sedentary lifestyle is reinforced as the students who are BVI grow older, as younger children tend to be more active than older children (Ayvazoglu \& Kozub, 2006; Longmuir \& Bar-Or, 2000).

This study investigated social influences on attraction to physical activity and perceived physical competence among youth who are BVI or DHH. Specifically, what is the perceived influence that parents and peers have on attraction to physical activity among children who are BVI and/or DHH? Various predictors of children's physical activity-related beliefs and involvement were examined among children who have visual or hearing impairments with particular reference to parental and peer forms of influence. Currently, children with disabilities are severely underrepresented in the pediatric exercise and sport literature and minimal research has sought to examine the predictors and variables associated with low participatory involvement of this population in sport and physical activity. Research supports the view that parental and peer beliefs and behaviors are related to children without disabilities' interest in physical activity (Babkes \& Weiss, 1999; Brustad, 1996) but little research has examined predictors and patterns of interest and physical activity involvement among children who are BVI or DHH.

\section{Research Purpose}

This study was part of a larger study that employed a mixed-methods approach. The 
Children's Attraction to Physical Activity or CAPA survey (Brustad, 1996) consists of a quantitative survey, and qualitative interviews to gain information on the perceptions of parental influence of children who were BVI or DHH. The students were selected for the interview process based on recommendations of the teachers and their availability during the research days.

\section{Study Design}

\section{Methods}

This study utilized the qualitative data set of the larger study. Eleven youth between the ages of 10-18 were interviewed, six were BVI and five were $\mathrm{DHH}$. There were five males (three BVI, two DHH) and six females (three BVI, three $\mathrm{DHH})$. The interviews consisted of 23 questions broken into 3 sections. Each individual interview took approximately one hour. At the time of the study, the participants attended a residential and day school for students who are BVI and/or DHH. The school is located in a western state and is broken into two sub-schools by disability (BVI and DHH). Each of the sub-schools functions with its own teachers and principal. There is not much interaction between the schools in terms of sports or programs.

Nine of the study participants lived at the school full time year round except during the summer break. The other two participants were day students who commute daily from home to school five days per week. Each of the participants had no other physical or mental impairments, and could understand and respond appropriately to the questions.

This study was approved by the IRB committee of the university prior to contacting the schools. The principals of the schools were contacted almost a year in advance of the study. Once permission was received from the schools, the principals and teachers contacted the parents of potential participants for this study. Parents of potential candidates were given the opportunity to make contact with the researchers on behalf of their children. Consent forms were sent by the school to the parents. Once parents consented, the students were given an assent form for them to sign if they agreed to participate. In some cases the principal was afforded guardianship of the youth and gave his consent to the project in lieu of the parents.

\section{Measures}

The youth were given the Children's Attraction to Physical Activity (CAPA) survey for the quantitative aspect of the study (Brustad, 1996) which measures their attraction to differing types of physical activity. Eleven students were then selected from those eligible (i.e. without any cognitive disabilities that would not allow them to comprehend the questions). The interviews were conducted by the researchers with a representative from the school present in an available empty classroom or in a spare room in the school office. Sign language interpreters were provided for the students who were DHH. Due to restrictions on visits and availability of the students, the interviews took place over two separate days and lasted approximately 30-45 minutes each. The interviews were digitally recorded by the researchers and transcribed verbatim. For students who are $\mathrm{DHH}$, the voices of the interpreters were recorded as the students gave their responses to the interview questions. In the transcriptions, the students were given pseudonyms, and the original data and all references to student names were destroyed.

\section{Data Collection}

An interview protocol was used for the formal interviews. The interview questions were based on the CAPA survey (Brustad, 1993; 1996). The CAPA survey was developed from Harter's (1983) competence motivation theory in that children are essentially attracted to (have intrinsic motivation for) activities in which they feel competent. The protocol guide consisted of questions concerning the child's attraction to physical activity, the child's perceived physical competence, and the child's perceived parental influence for both parents. Deductive analytic induction was used for analysis (Taylor \& Bogdan, 1984). This type of approach is often used to test a previous theory in a different situation. Previous CAPA findings were available for mainstream populations indicating these categories: motivation to be physically active or play sport, perceptions of physical competence, and perceived influence of their 
parents and peers on physical activity and sport involvement Deductive analysis was utilized in this study to use previous CAPA results to aid in the analyses of the data.

\section{Trustworthiness}

Triangulation of various data sources, including interviews, questionnaires, and staff data was used to ensure trustworthiness. Comparisons were made with the quantitative data and no irregularities were found. Peer-debriefing amongst the researchers and school staff was also used to verify the validity of the data. Member checks were conducted with nine of the youth available during that visit to corroborate the findings and ensure confirmability (Schwandt, 2001). Findings were explained verbally for the students who were BVI.

\section{Results}

Deductive content analysis revealed a number of meaningful themes related to the previous CAPA survey results. Reported attraction to physical activity and sport is similar between both groups at the residential school reported high levels of interest in a variety of sports and physical activities. However, youth with DHH described a higher level of sport and a wide variety of physical activity experience and more favorable perceptions associated with involvement than youth with BVI.

These results were expressed in the themes of motivation to be physically active or play sport, perceptions of physical competence, and perceived social influence of parents/peers. Several themes and sub-themes were found for each of these categories. These were derived from the answers of all eleven participants and were both positive and negative. Table 1 . illustrates this by showing the average number of times per participant that their responses fit each category.

Table 1

Frequency Counts for Theme Comments from 11 participants

\begin{tabular}{|c|c|c|c|}
\hline \multirow[t]{2}{*}{ CAPA Theme } & \multirow[t]{2}{*}{ Example } & \multicolumn{2}{|c|}{ Frequency Counts } \\
\hline & & Average & $\begin{array}{l}\text { Standard } \\
\text { Deviation }\end{array}$ \\
\hline $\begin{array}{l}\text { Motivation to be } \\
\text { physically active or } \\
\text { play sport } \\
\text { Negative example of } \\
\text { Motivation Theme }\end{array}$ & $\begin{array}{l}\text { "I love playing sports. Uh, I've been playing } \\
\text { ever since I... you know my whole life..., I } \\
\text { love it!" } \\
\text { "Because I'm a girly girl I thought it } \\
\text { [exercising] was absolutely disgusting!" }\end{array}$ & 6.8 & 1.1 \\
\hline $\begin{array}{l}\text { Perceptions of physical } \\
\text { competence }\end{array}$ & $\begin{array}{l}\text { "I'm the best thrower on my team and I've } \\
\text { been told that by my coach and other kids on } \\
\text { my team." }\end{array}$ & 4.2 & 1.0 \\
\hline $\begin{array}{l}\text { Negative example of } \\
\text { Perception Theme } \\
\text { Perceived social } \\
\text { influence of } \\
\text { parents/peers }\end{array}$ & $\begin{array}{l}\text { "It's kind of hard for me to pick them [games] } \\
\text { up." } \\
\text { Parents: "My dad...he buys the equipment but } \\
\text { he doesn't play." } \\
\text { Peers: "we always give each other a lot of } \\
\text { support and feedback and say 'good game'" }\end{array}$ & 1.9 & 0.31 \\
\hline $\begin{array}{l}\text { Negative example of } \\
\text { Perceived Theme }\end{array}$ & $\begin{array}{l}\text { Parents: "No, she does not want me to play } \\
\text { sports, school first." } \\
\text { Peers: "What I've noticed in high school, } \\
\text { people really don't' care anymore because } \\
\text { kids have been mean to them or something } \\
\text { else happens that they don't like to play games } \\
\text { anymore" }\end{array}$ & 3.6 & 0.5 \\
\hline
\end{tabular}




\section{Attraction to Physical Activity}

In the first CAPA category, attraction to physical activity, two sub-themes emerged. The first theme indicated the fun of physical exertion and vigorous physical activity for these participants. There was an obvious dichotomy between male and female students. For instance, the males in both BVI and DHH groups reported enjoying the experiences of getting sweaty and breathing hard. Tom, a male student who was BVI suggested "I kind of sort of like it. You're being active and you're um you're heart rate is going and stuff like." Frankie, another male student who was DHH, stated "Like playing hard is good. And so, exercise is good. But I wish I could do it every day. Like I could go to the gym every single day. I wish I could do that."

Females, in both groups, described enjoying the experience of exertion as well, although not as strongly as the males. Jordan, a BVI student, said "I love it $100 \%$. Um, I just think it's a good way to release stress. It's a good way to just get out and do something with yourself and at the same time you're doing something good for your body." However, the girls also claimed not to like getting sweaty. For instance Debra stated, "I don't like that. Ha! Because you get all sweaty and sticky." Sue supported Debra's claim. She said, "I'm a girly girl I thought it was absolutely disgusting, lol."

Another sub-theme was their enjoyment of games and sports. The males reported enjoying football and basketball (DHH), and wrestling and track (BVI/DHH). Females described liking goal ball (BVI), basketball (DHH), and cheerleading (BVI/DHH). Sharon suggested, "I love playing sports. Uh, I've been playing ever since I... you know my whole life. I'm used to it, I love it!" Megan agreed. She said, "Oh, I love games, they're a lot of fun to play. Sports are so much fun you know I just really enjoy it. Ah, getting out there you know, winning, racing, running track, doing the jump. I just love it. It's fun. I keep running as hard as I can and hang out with other friends. I know a couple of hearing people and we try to talk back and forth about sports but it is fun!"

\section{Perceived Physical Competence}

The second CAPA result was perceived physical competence. Perceved competence was high with both groups, as most of the students who are BVI or DHH reported that they were "good players," while a few reported being at least fair in skill. For instance, students put forth statements suggesting that they were good at the games and activities they pursued. For example, Sharon, a studen who was BVI, suggested "I think I'm a good goal ball player." Tom's comment was similar; he said "I'm fairly good even though I have a visual impairment. I can do just about the same amount as a person who doesn't have visual impairment, I'm actually pretty good. I usually, um...every time I play a game or something like that I usually win." These statements were usually supported by referencing what their parents or coaches told them. Tom said, "I'm the best thrower on my team and I've been told that by my coach and other kids on my team."

However, the students' optimism waivered if they were asked to compare themselves to others. As reported by Sharon (BVI), who stated above that she was good, "Um, with the team, I'm, I'm okay I'm fair. I think I still need some more practice and um, most of my teammates have more experience than I do. I only have two years of experience. My friends have four." Students, both BVI and DHH, also reported having trouble with games they had not played before. This was particularly true of games played outside as illustrated by Jenny, a student who was (DHH). She said, "Outdoor games? No, I'm not really; I don't pick it up quickly enough so I don't like it."

\section{Influence on Attraction to Physical Activity}

The third CAPA result was social influence on attraction to physical activity which was broken down into parents and peers. In terms of parental influence, the students reported that overall, there was little parental encouragement for sport and physical activity in both BVI and DHH groups. This minimal support included granting permission and purchasing equipment. There was no hindrance either, and the parental support was typically related to how active the child was. For instance Jake, a school athlete who was DHH, commented that his father "buys 
us like soccer balls and basketballs and stuff like that, and put up a basketball net in the backyard". Other than he doesn't [do much], he buys the equipment but he doesn't play." Parents were typically reported as saying "school first, then sports" and often withdrawing the students from things their parents said they couldn't do and promoting the things they thought they could do.

For both youth who are BVI and for those who are $\mathrm{DHH}$, peers at school were perceived as supportive. Emily, a student who was BVI, stated, "You know, um, we always give each other a lot of support and feedback and say 'good game' and you know we give each other a lot of support and help each other out." A few students who were DHH reported that they were occasionally asked and played with students who were sighted and non-DHH. This often made youth who are DHH/BVI uncomfortable. Frankie suggested, "I enjoy being with other students and not here (at the school). You know, being out with like hearing students. And I enjoy playing and exercising like wrestling with them and it makes me happy. And I play games with the deaf kids as well and we like chase each other and...play games." David disagreed. He said, "They just don't ask me. But um....like hearing kids sometimes they'll ask me. Uh....they'll ask me to play with me and I'll maybe say yes. But it's too rare, it is weird too."

\section{Discussion}

This study investigated social influences on attraction to physical activity and perceived physical competence among youth who are BVI or DHH and the perceived influence that parents and peers have on attraction to physical activity among children who are blind or visually impaired or deaf. Specifically, the investigators sought a deeper understanding of this population's attraction to physical activity with regard to their motivation to be physically active or play sport, perceptions of physical competence, and perceived social influence of parents/peers.

Reported attraction to physical activity and sport was evident in that both groups reported high levels of interest in a variety of sports and physical activities. However, youth with DHH described a higher level of sport and a wide variety of physical activity experience and more favorable perceptions associated with involvement than youth with BVI. More opportunities were available to participate with sighted and hearing students which is not surprising as sports like baseball, basketball, and football that utilize visual tracking skills are inherently more difficult for youth who are BVI than for youth who are DHH.

It was also noteworthy that the level of attraction to physical activity among this sample of youth with disabilities was similar to previous findings of mainstream youth populations (Brustad, 1996; Seelye, 1983). Both groups (BVI and $\mathrm{DHH}$ ) described an attraction to physical activity and sport. This is illustrated in Table 1. as the ratio of positive to negative comments was approximately three to one. Unfortunately, this attraction to physical activity/sport by youth did not translate into similar levels of reported participation. Alarmingly, this trend towards inactivity tends to remain consistent into adulthood with these populations often resulting in a lower quality of life (Capella-McDonnall, 2007; Holbrook, et al., 2009; Rimmer, Riley, Want, Rauworth, \& Jurkowski, 2004 ).

Despite their desires, these students are not reporting the levels of activity that would be consistent with mainstream youth with comparable CAPA scores. Various hindrances to physical activity may account for this mismatch. The participants reported several of these barriers including: lack of parental encouragement, modeling, and participation;. Other potential barriers may include lack of opportunities for participation including facilities, trained staff, and or special equipment needed for youth with special needs (Rimmer, et al., 2007). Engagement in the physical domain may be imperative for individuals with visual and hearing impairments. Increased exercise can help to avoid co-morbidities of inactivity, increase opportunity for favorable social

interactions, and increase positive selfperceptions (Capella-McDonnall, 2007; Holbrook, et al., 2009). 


\section{Table 1}

Frequency Counts for Theme Comments from 11 participants

\begin{tabular}{|c|c|c|c|}
\hline \multirow[t]{2}{*}{ CAPA Theme } & \multirow[t]{2}{*}{ Example } & \multicolumn{2}{|c|}{ Frequency Counts } \\
\hline & & Average & $\begin{array}{l}\text { Standard } \\
\text { Deviation }\end{array}$ \\
\hline $\begin{array}{l}\text { Motivation to be } \\
\text { physically active or } \\
\text { play sport }\end{array}$ & $\begin{array}{l}\text { "I love playing sports. Uh, I've been playing } \\
\text { ever since I... you know my whole life..., I } \\
\text { love it!" }\end{array}$ & 6.8 & 1.1 \\
\hline $\begin{array}{l}\text { Negative example of } \\
\text { Motivation Theme }\end{array}$ & $\begin{array}{l}\text { "Because I'm a girly girl I thought it } \\
\text { [exercising] was absolutely disgusting!" } \\
\text { "I'm the best thrower on my team and I've }\end{array}$ & 2.1 & 0.7 \\
\hline $\begin{array}{l}\text { Perceptions of } \\
\text { physical competence }\end{array}$ & $\begin{array}{l}\text { been told that by my coach and other kids on } \\
\text { my team." }\end{array}$ & 4.2 & 1.0 \\
\hline $\begin{array}{l}\text { Negative example of } \\
\text { Perception Theme }\end{array}$ & $\begin{array}{l}\text { "It's kind of hard for me to pick them } \\
\text { [games] up." }\end{array}$ & 2.1 & 0.7 \\
\hline$\frac{\text { Perceived social }}{\text { influence of }}$ & $\begin{array}{l}\text { Parents: "My dad...he buys the equipment } \\
\text { but he doesn't play." }\end{array}$ & 1.9 & 0.31 \\
\hline parents/peers & $\begin{array}{l}\text { Peers: "we always give each other a lot of } \\
\text { support and feedback and say 'good game'" }\end{array}$ & 3.6 & 0.5 \\
\hline & $\begin{array}{l}\text { Parents: "No, she does not want me to play } \\
\text { sports, school first." }\end{array}$ & 2.5 & 0.8 \\
\hline $\begin{array}{l}\text { Negative example of } \\
\text { Perceived Theme }\end{array}$ & $\begin{array}{l}\text { Peers: "What I've noticed in high school, } \\
\text { people really don't' care anymore because } \\
\text { kids have been mean to them or something } \\
\text { else happens that they don't like to play } \\
\text { games anymore" }\end{array}$ & 1.909091 & 0.301511 \\
\hline
\end{tabular}

Potential limitations of the study included a low sample size of students from one setting. However, from a qualitative perspective these are an acceptable number of participants. These were also not considered limitations as the researchers sought a deeper understanding of this specific populations' attraction to physical activity rather than to generalize to all students who are BVI and DHH.

\section{Future Research}

This study supports previous research findings (Capella-McDonnall, 2007; Ellis, 2001; Harrison, 2006). suggesting the need for more research about the nature of family and peer influences upon students who are BVI or DHH. It is important to note that although populations with BVI and DHH have different needs and desires, it is unfortunate that they share similar barriers to increasing their physical activity. This suggests that future research on these barriers, including peer and parental involvement, could potentially benefit all low incidence groups who share similar barriers by designing and implementing opportunities for children of all abilities to become involved exercise and in sport programs. This is more important as changes in the economy creates a collapse of services offered to children with low incidence disabilities. Often these students are now sharing facilities (such as this residential school) and staff (adapted physical education teachers, professionals, and itinerant specialists). In this climate of cutting services, it is imperative to understand and potentially circumvent these barriers to their being physically active, so that all children can enjoy the benefits. 


\section{References}

Ayanvazoglu, N. R., Oh, H. K., \& Kozub, F. M. (2006). Explaining physical activity in children with visual impairments: A family systems approach. Council for Exceptional Children, 72(2), 235248.

Babkes, M., \& Weiss, M. (1999). Parental influence on cognitive and affective responses in children's competitive soccer participation. Pediatric Exercise Science, 11, 44-62.

Bishop, V. (2000). Early Childhood. In A. Koenig, \& M. Holbrook (Eds.), Foundations of Education (2 $2^{\text {nd }}$ Ed.) Volume 2: Instructional strategies for teaching children and youths with visual impairment (pp. 225-263). New York: AFB Press.

Brooks, H., Ellis, G. (1982). Self-esteem of hearing impaired adolescents: effects of labeling. Youth \& Society, 14(1), 59-81.

Brown, D. W., Balluz, L. S., Heath, G. W., Moriarty, D. G., Ford, E. S., Giles, W. H., \& Mokdad, A. H. (2003). Associations between recommended levels of physical activity and health-related quality of life; Findings from the 2001 Behavioral Risk Factor Surveillance System (BRFSS) Survey. Preventive Medicine, 37, 520-528.

Brustad, R.J. (1993). Who will go out and play? Parental and psychological influences on children's attraction to physical activity. Pediatric Exercise Science, 5, 210-223.

Brustad, R. (1996). Attraction to physical activity in urban schoolchildren: parental socialization and gender. Research Quarterly for Exercise and Sport, 67(3), 316-324.

Capella-McDonnall, M. (2007). The Need for Health Promotion for Adults Who Are Visually Impaired. Journal of Visual Impairment \& Blindness, 101,133-145.

Dempsey, J. M., Kimiecik, J. C., \& Horn, T. S. (1993). Parental influence on children's moderate to vigorous physical activity participation: an expectancy value approach. Pediatric and Exercise Science, 5, 151-167.

Ellis, M. K. (2001). Influences of parents and school on sports participation and fitness levels of deaf children. Palestra, 17(1), 44-50.

Fiorini, J., Stanton K., \& Reid, G. (1996). Understanding parents and families of children with disabilities: considerations for adapted physical activity. Palaestra, 12(2), 16-23.

Gosch, A., Bambring, M., Gennat, H., \& Rohlmann, A. (1997). Longitudinal study of neuropsychological outcomes in blind extremely low birth weight children. Developmental Medicine and Child Neurology, 39, 297-304.

Harrison, T. (2006). Health promotion for persons with disabilities: What does the literature reveal? Family and Community Health, 29(1), 12S-19.

Harter, S. (1983). Developmental perspectives on the self-system. In P. H. Mussen (Ed.), Handbook of Child Psychology, (Volume IV, 4th edition, pp. 275-385). New York: Wiley.

Holbrook, E. A., Caputo, J. L., Perry, T. L., Fuller, D. K., \& Morgan, D. W. (2009). Physical activity, body composition, and perceived quality of life. Journal of Visual Impairment \& Blindness, 103, 17-29.

Kiavina, A., \& Roswal, G. (2003). Assessment of sport teachers attitudes and opinions toward adapted physical education. Research Quarterly for Exercise and Sport, March 12003.

Kozub, F. M., \& Oh, H. (2004). An exploratory study of physical activity levels in children and adolescents with visual impairments. Clinical Kineseology, 58(3), 1-7.

Letcher, K. (n.d.) Adapted physical education for the blind and visually impaired. Retrieved January 11, 2005 from http://www.obs.org/parent/articles\%20of\%20interest/adapted_physical education_for_htm.

Lieberman, L., Byrne, H., Mattern, C, Watt, C., \& Fernandez-Vivio, M. (2010). Health related fitness of youths with visual impairments. Journal of Visual Impairment \& Blindness, 104(6), 349-359.

Lieberman, L., \& Houston-Wilson, C., (1999), Overcoming the barriers to including students with visual impairments and deaf-blindness in physical education. [Electronic version]. Review, 31 (3), 129. 
Lieberman, L., Houston-Wilson, C., \& Kozub, F. (2002), Perceived barriers to including students with visual impairments in general physical education. Adapted Physical Activity Quarterly, 19(3), 364-377.

Lieberman, L., \& Wilson, S. (2005). Effects of a sport camp practicum on attitutudes toward children with visual impairments and deafblindness. Re:View, 36(4), 141-153.

Longmuir, P. E., \& Bar-Or, O. (2000). Factors influencing the physical activity levels of youths with physical and sensory disabilities. Adapted Physical Activity Quarterly, 17, 40-53.

Morgan, W. (1994). Physical activity and psychosocial outcomes. In C. Bouchard, R. J. Shepard, \& T. Shephens (Eds.), Physical activity, fitness and health: International proceedings and consensus statement (pp. 851-867). Champaign, IL: Human Kinetics.

Rimmer, J. H., Riley, B., Wang, E., Rauworth, A., \& Jurkowski, J. (2004). Physical activity participation among persons with disabilities: Barriers and facilitators. American Journal of Preventive Medicine, 26, 419-425.

Robinson, B., Lieberman, L., \& Rollheiser, H. (2005). Students with visual impairments' attitudes toward variables in general physical education classes. Unpublished manuscript, State university of New York, College at Brockport

Sacks, S., \& Silberman, R. (2000). Social Skills. In A. Koenig Move up \& M. Holbrook (Eds.), Foundations of Education (2 $2^{\text {nd }}$ Ed.) Volume 2: Instructional strategies for teaching children and youths with visual impairment (pp. 616-652). New York: AFB Press.

Schwandt, T.A. (2001). Dictionary of Qualitative Inquiry. $2^{\text {nd }}$ e. London: Sage Publications.

Seelye, W. (1983). Physical fitness of blind and visually impaired Detroit public school children. Journal of Visual Impairment \& Blindness, 77, 117-118.

Simons-Morton, D. G., Obarzanek, E., \& Cutler, J. A. (2006). Obesity researchLimitation of methods, measurements, and medications. Journal of the American Medical Association, 295(7), 826-828.

Stewart, D., \& Ellis, K. (2005). Sports and the Deaf Child. American Annals of the Deaf, 150(1). 59-66.

Stuart, M. E., Lieberman, L., \& Hand, K. E. (2006). Beliefs about physical activity among children who are visually impaired and their parents. Journal of Visual Impairment \& Blindness, April, 223234.

Taylor, S. J., \& Bodgen, R. (1984). An introduction to qualitative research methods: the search for meaning. $2^{\text {nd }}$ ed. New York: John Wiley.

Tepfer, A. (2002). Socialization into sport and barriers encountered by elite blind athletes. Unpublished Master's Thesis State University of New York at Brockport, Brockport, NY.

U.S. Department of Health and Human Services (2000). Healthy people 2010: understanding and improving health and objectives for improving health ( ${ }^{\text {nd }}$ ed., 2 vols.) Washington, DC: U.S Government Printing office.

Walker, S. (1992). Physical and outdoor education as active life skills for visually handicapped children and young people. Royal National Institute for the Blind. Retrieved January 11, 2005 from http://www.rnib.org.uk/xpedio/groups/public/documents/Visugate/public_getoffgr.hcsp.

Wiskochil, B., Lieberman, L.,Houston-Wilson, C., \& Petersen, S. (2007). The effects of trained peer tutors on the physical education of children who are visually impaired. Journal of Visual Impairment \& Blindness, 101(6), 339-350.

Williams, A. (1988) Physical activity patterns among adolescents-Some curriculum implications. Physical Education Review, 11 (1), 28-39.

Author Information

*Stefan Ward, PhD

Central Washington University 
Ward, S., Farnsworth, C., Babkes, M., \& Perrett, J. / Californian Journal of Health Promotion 2012, Volume 10, Issue 1, 82-91

\author{
Charles Farnsworth, EdD \\ University of Northern Colorado \\ Megan Babkes, Phd \\ University of Northern Colorado \\ Jamis Perrett, $\mathrm{PhD}$ \\ Texas A\&M University \\ * corresponding author
}

